$\mathrm{EXETERR}$

\title{
A Momentum Trading Strategy Based on the Low Frequency Component of the Exchange Rate
}

\author{
Richard D.F. Harris \\ University of Exeter \\ Fatih Yilmaz \\ Bank of America
}

Paper Number: 08/04

August 2008

\begin{abstract}
In this paper, we develop a momentum trading strategy based on the low frequency trend component of the spot exchange rate. Using, alternately, kernel regression and the high-pass filter of Hodrick and Prescott (1997), we recover the non-linear trend in the monthly exchange rate and use short-term momentum in this to generate buy and sell signals. The low frequency momentum trading strategy offers greater directional accuracy, higher returns and Sharpe ratios and lower maximum drawdown than traditional moving average rules. Moreover, unlike traditional moving average rules, the performance of the low frequency momentum trading strategy is relatively robust across different time periods, and to the choice of smoothing parameters across a wide range of values.
\end{abstract}

Keywords: Momentum; Moving average rules; Hodrick-Prescott filter; Kernel regression; Trading strategy.

Address for correspondence: Professor Richard D. F. Harris, Xfi Centre for Finance and Investment, University of Exeter, Exeter EX4 4PU, UK. Tel: +44 (0) 1392 263215, Fax: +44 (0) 1392263242 Email: R.D.F.Harris@exeter.ac.uk. 


\section{Introduction}

The existence of momentum - or positive serial correlation - in short horizon financial asset returns has been firmly established in the academic literature. ${ }^{1}$ In the foreign exchange market, momentum in spot exchange rates has been widely exploited in trading strategies used by currency fund managers and commodity trading advisors. Indeed, for short horizons, foreign exchange dealers are more likely to use technical indicators, such as those that exploit momentum, than to base their forecasts on economic fundamentals. ${ }^{2}$ The single most important momentum trading strategy in the foreign exchange market is the moving average (MA) rule, in which buy and sell signals are generated by the intersection of averages of the current and lagged spot exchange rate over different horizons. MA rules are widely used in the currency fund management industry, either directly as a trading indicator or indirectly as a benchmark for other, more sophisticated momentum trading strategies. In the academic literature, a number of studies have demonstrated that MA rules are able to systematically generate excess returns in the foreign exchange market over a buy-andhold strategy. Moreover, while there remains some contention about the source of these excess returns, the evidence suggests that they are not simply compensation for transaction costs or risk. ${ }^{3}$

The success of momentum trading strategies hinges on the extraction of a non-linear trend forecast from the spot exchange rate. The success of such strategies is limited by the fact that the spot exchange rate comprises a substantial 'noise' component, which makes identification of any trend particularly difficult. For example, a two-period moving average rule - which is very commonly used in practice to detect momentum in monthly exchange rates - infers a positive trend if the current month's spot rate is

${ }^{1}$ See, for example, Jegadeesh and Titman (1993, 2001), Chan, Jegadeesh and Lakonishok (1996) and Korajczyk and Sadka (2004). Rouwenhorst (1998) and Chan (2000) demonstrate that momentum is not confined to the US equity market. In the context of the foreign exchange market, see, for example, Levich $(1985,1989)$, Kritzman (1989) and Taylor (1992).

${ }^{2}$ See, for example, the survey by Taylor and Allen (1992).

${ }^{3}$ See, for example, Sweeney (1986), Taylor and Allen (1992), Levich and Thomas (1993), Taylor (1994), Szakmary and Mathur (1997), Neely (1997), Neely, Weller and Ditmar (1997), LeBaron (1999), Okunev and White (2003) and Olson (2004). Kho (1996) finds that the profitability of moving average rules is partly due to a timevarying risk premium. 
higher than the previous month's spot rate, and a negative trend if it is lower. While an increase in the exchange rate is indeed consistent with the existence of a positive trend, it is of course also consistent with a zero (or indeed negative) trend that is contaminated by noise in either the current month's exchange rate or last month's exchange rate, or both. Increasing the number of lags used in the MA rule reduces the impact of the irregular component in the spot exchange rate, but also reduces the responsiveness of the rule to cyclical turning points, which limits its effectiveness as a trading indicator. Moreover, since the structure of an MA rule is not formally derived from the time-series properties of the exchange rate (in contrast with an ARMA model or a Markov switching model, for example), the choice of the MA horizon is problematic (see, for example, Brock, Lakonishok and LeBaron, 1992; Neely, Weller and Dittmar, 1997). The successful implementation of an MA rule therefore requires subjective calibration using in-sample data, and is consequently as much art as it is science.

In this paper, we take an alternative, more rigorous approach to the identification of the non-linear trend from the spot exchange rate. In particular, we develop a low frequency momentum trading strategy that is based on a decomposition of the spot exchange rate into its regular and irregular components. We use short-term momentum in the low frequency trend component to generate directional forecasts of the spot exchange rate. In order to decompose the spot exchange rate into its regular and irregular components, we employ two approaches. The first is the high-pass filter of Hodrick and Prescott (1997), which extracts a low frequency non-linear trend from a time-series, the smoothness of which is determined by a pre-specified smoothing parameter. The second is kernel regression, which estimates the local trend of a timeseries as a weighted average of the sample data, with the weights determined by the choice of kernel distribution and a bandwidth parameter.

We apply the low frequency trading strategy to individual G10 ex-USD currencies against the USD, and to an equally weighted portfolio of these currencies, using monthly data over the period 1993-2008. We calculate the out-of-sample performance of the trading strategy both over the full sample and over three sub-samples. As a benchmark, we compare the low frequency momentum trading strategy to strategies that are based on a range of single and double MA rules, including ones that are 
widely used in practice. We find that the low frequency momentum trading strategy generates significantly higher returns and Sharpe ratios than those based on traditional MA rules, as well as lower maximum drawdown and greater directional accuracy. Unlike the MA rules, the performance of the low frequency momentum trading strategy is relatively robust to the choice of sample period. Importantly, the low frequency momentum trading strategy is also robust to the choice of smoothing parameter (in the case of the HP filter) and the distribution and bandwidth parameter (in the case of kernel regression) over a wide range of values.

The outline of the paper is as follows. In the following section we summarize the moving average rules that are commonly used in practice for the identification of trends in the spot exchange rate, and introduce the low frequency momentum trading strategy that is based on the decomposition of the exchange rate into its regular and irregular components. In Section 3, we describe the data used in the empirical section, and the methodology used to implement the MA and low frequency approaches. Section 4 reports the results of the empirical analysis. Section 5 provides a summary, some concluding remarks and suggestions for future research.

\section{Theoretical background}

Our starting point is a model for the spot exchange rate that comprises a regular and irregular component. Specifically, we assume that the spot rate, $S_{t}$, has the following decomposition

$$
S_{t}=S_{t}^{*}+v_{t}
$$

Where $S_{t}^{*}$ is a low-frequency, non-linear regular component (which may comprise both long-run trend and medium-run cycle components) and $v_{t}$ is a high-frequency, serially uncorrelated (though possibly heteroscedastic) process with $E\left[v_{t}\right]=0$ and $E\left[v_{t}^{2}\right]=\sigma_{v}^{2}<\infty$. It is assumed that the success of momentum based trading strategies 
comes from predictability in the low-frequency component, $S_{t}^{*}$, the nature of which we do not attempt to parameterise. ${ }^{4}$

As an illustration, and to motivate the model described above, Figure 1 shows the decomposition of the monthly USD/JPY spot exchange rate over the period 1986 to 2008 into trend, cycle and irregular components using the band-pass filter of Christiano and Fitzgerald (2003). The frequency of the cyclical component is arbitrarily set to between two and five years, and persistent shocks of greater than five years are attributed to the trend component. Figure 2 plots the aggregated trend and cycle components against the spot exchange rate. In this illustrative case, the regular components of the spot exchange rate are estimated using the whole data set and so the turning points of the spot exchange rate are of course captured perfectly. In practice, the success of momentum trading strategies critically depends on the ability to extract information about the regular component of the spot exchange rate using historical data, so that it can be used to generate effective out-of-sample trading signals.

[Figures 1 and 2]

\section{Trend identification using moving average rules}

Moving average (MA) rules are very commonly used to generate buy and sell signals from data on the spot exchange rate. The MA rule compares a short-run moving average of the current and lagged exchange rate with a long-run moving average, where ‘short-run' and 'long-run' are arbitrarily defined. The MA rule can be written as

$$
M A(m, n)=\frac{1}{m} \sum_{i=0}^{m-1} S_{t-i}-\frac{1}{n} \sum_{i=0}^{n-1} S_{t-i}, \quad \text { where } m<n
$$

\footnotetext{
${ }^{4}$ The obvious source of predictability in $S_{t}^{*}$ is serial correlation arising from, for example, the interaction between noise traders and central bank intervention (see, for example Szakmary and Mathur, 1997; LeBaron, 1999). However, it is also possible that predictability in $S_{t}^{*}$ is caused by non-linear dependence in the form of persistent shocks to the higher moments of the distribution of exchange rates. For a recent analysis of the link between conditional volatility, for example, and directional predictability, see Christoffersen and Diebold (2006).
} 
The MA rule generates a buy signal when $M A(m, n)>0$, and a sell signal when $M A(m, n)<0$. Using the decomposition given by (1), it is straightforward to show that a buy signal is therefore generated when

$$
\frac{1}{m} \sum_{i=0}^{m-1} S_{t}^{*}+\frac{1}{m} \sum_{i=0}^{m-1} v_{t}>\frac{1}{n-m} \sum_{i=m}^{n-1} S_{t}^{*}+\frac{1}{n-m} \sum_{i=m}^{n-1} v_{t}
$$

The MA rule therefore compares a noisy measure of the average value of the trend component over the previous $m$ periods (which can be thought of as the 'current' value of the trend) with a noisy measure of its average value over the preceding $n-m$ periods (which can be thought of as the 'lagged' value of the trend). The MA rule therefore works by testing whether the trend has risen (in which case a buy signal is generated) or fallen (in which case a sell signal is generated). The biggest challenge in implementing the MA rule is the choice of the lag parameters, $m$ and $n$. The purpose of averaging the exchange rate is to mitigate the effect of the irregular component, $v_{t}$. However, in averaging the exchange rate, information about the trend, $S_{t}^{*}$, is lost, particularly when the trend is not monotonically increasing or decreasing over the horizon of the MA rule. In particular, increasing $m$ and $n$ reduces the impact of the irregular component in the spot exchange rate (which tends to increase the effectiveness of the trading strategy), but simultaneously reduces the responsiveness of the rule to cyclical turning points (which tends to decrease the effectiveness of the trading strategy). The exact choice of $m$ and $n$ therefore tends to be an empirical matter and in practice is often calibrated using in-sample data. This can lead to a lack of robustness in out-of-sample forecasting, since the optimal choice of $m$ and $n$ tends to be sample-specific. Note also that the MA rule is likely to be inefficient since it attaches equal weight to all observations that the average comprises, yet more recent observations are, in practice, likely to contain more information about the current value of the trend than are more distant observations. For monthly exchange rates, the mostly widely used MA rule in the fund management industry is $M A(1,2)$, which amounts to comparing the current exchange rate with the one-period lagged exchange rate. The $M A(1,2)$ is responsive to cyclical turning points in the exchange rate (because it does not smooth the exchange rate), but also erroneously responds to 
spurious changes in the direction of the trend that arise from the noise component in the exchange rate.

Trend identification using the low-frequency component of the exchange rate

The success of momentum trading rules relies on identification of the non-linear trend component of the spot exchange rate, $S_{t}^{*}$, and in particular, on forecasting changes in the direction of this trend. MA rules achieve this by comparing average values of the spot exchange rate over arbitrary horizons. Here we take an alternative, more rigorous approach to the identification of the regular component of the spot exchange rate. In particular, we directly estimate the low frequency trend component of the spot exchange rate and employ this in a momentum trading strategy. In order to extract the non-linear trend component from the exchange rate, we use two methods. The first is the high-pass filter of Hodrick and Prescott (1997), which minimises the sum of squared deviations between the observed series and the unobserved low frequency component that is to be recovered, while penalising variation in the low frequency component. More formally, the HP filter estimates the non-linear trend as

$$
S_{t}^{*}=\underset{\left\{S_{t}^{*}\right\}_{t=1}^{T}}{\operatorname{argmin}}(t)\left[\sum_{t=1}^{T}\left(S_{t}-S_{t}^{*}\right)^{2}+\lambda \sum_{t=2}^{T-1}\left[\left(S_{t+1}^{*}-S_{t}^{*}\right)-\left(S_{t}^{*}-S_{t-1}^{*}\right)\right]^{2}\right]
$$

where $\operatorname{Argmin}(t)$ is the $t$ th observation of the series that minimises the objective function. The first term in (4) penalises deviations of the observed series from the low-frequency trend, while the second term penalises instability in the trend using its second derivative and a smoothing parameter, $\lambda$. When $\lambda=0$, the trend is equal to the original series, while as $\lambda$ approaches infinity, it converges towards a linear trend. The HP filter therefore represents a trade-off between the goodness-of-fit of the lowfrequency trend component and its smoothness. While there is no 'correct' value for the smoothing parameter, $\lambda$, a common choice in the literature for macroeconomic data is 100 multiplied by the squared frequency of the data (see, for example, Baxter and King, 1999). 
The second approach that we take is kernel regression, which is a non-parametric estimator that can be used to recover an unknown non-linear functional relationship between a dependent variable and a vector of independent variables. In the present case, the dependent variable is the spot exchange rate, and the independent variable is time. The non-linear trend is estimated as a weighted average of the independent variable, given by

$$
S_{t}^{*}=\sum_{\tau=\tau_{0}}^{\tau_{1}} w(t, \tau) S_{\tau}, \quad \text { where } \sum_{\tau=\tau_{0}}^{\tau_{1}} w(t, \tau)=1
$$

The weighting scheme can be determined by reference to a parametric distribution, which leads to the Nadaraya and Watson (1964) kernel estimator, given by

$$
S_{t}^{*}=\frac{\sum_{\tau=\tau_{0}}^{\tau_{1}} K_{h}(t-\tau) S_{\tau}}{\sum_{\tau=\tau_{0}}^{\tau_{1}} K_{h}(t-\tau)}
$$

Here, $K_{h}$ is the density function (or kernel) that determines the shape of the weighting scheme, and the bandwidth parameter, $h$, determines the size of the weights by modifying the standard deviation of the kernel. The kernel is evaluated over the domain $\tau_{0}, \ldots, \tau_{1}$. The larger the bandwidth parameter, the more weight is given to distant observations in fitting the non-linear trend at a particular point, and hence the smoother the recovered function. The bandwidth parameter is typically chosen with reference to the scale of the data, measured by either the standard deviation or, to mitigate the effect of outliers, the inter-quartile range (see, for example, Wand and Jones, 1995).

\section{Data and methodology}

Data

The moving average and low frequency momentum trading strategies are applied to monthly data on the G10 ex-USD currencies (EUR, JPY GBP, CHF, SEK, NOK, 
AUD, CAD and NZD) measured against the USD. We also consider an equally weighted portfolio of these currencies, which measures the level of the USD and thus allows us to examine the profitability of a generic USD trading strategy. End-ofmonth exchange rates for the period June 1986 to May 2008 were obtained from Reuters. Money market rates, which are used to calculate the 'carry' component of the trading strategy returns, were obtained from DataStream. The period June 1986 to May 1993 is reserved for initial estimation of the non-linear trend models, while the period June 1993 to May 2008 is used for out-of-sample evaluation of the different trading strategies. The out-of-sample period is further divided into three sub-samples (June 1993 to May 1998, June 1998 to May 2003 and June 2003 to May 2008) in order to examine the robustness of the various trading strategies in terms of temporal stability. Table 3 reports summary statistics for log returns for the nine individual exchange rates and the equally weighted portfolio. Panel A reports the mean, standard deviation, skewness and excess kurtosis, while Panel B reports the first six autocorrelation coefficients. P-values are reported in parentheses to test the null hypothesis that the autocorrelation coefficient is equal to zero.

\section{[Table 1]}

With the exception of EUR and CHF, all of the return series are highly non-normal with positive excess kurtosis and, in most cases, negative skewness. The volatility of individual currencies ranges from 1.74 percent for NOK to 3.32 percent for JPY. The volatility of the EWP is significantly lower (at 0.79 percent) owing to the effect of diversification. Many of the series display very significant first order autocorrelation, although notably the EWP does not. In some cases, there are significant autocorrelation coefficients at longer lags, although there does not appear to be a systematic pattern across currencies. It is important to note that while the existence of significant autocorrelation in currency returns is might be a sufficient condition for the effectiveness of technical trading rules, it is by no means a necessary condition. This is because technical trading rules exploit both linear and non-linear dependence in returns, while the reported autocorrelation coefficients measure only linear dependence. In particular, technical trading rules potentially exploit predictability in the exchange rate that might arise from persistent shocks to volatility, skewness and kurtosis (see, for example, Christoffersen and Diebold, 2006; Chistoffersen et al., 
2007). Thus, while the returns of the EWP do not display linear dependence, one should not assume that the technical trading rules (such as the MA filter or the low frequency approach proposed here) will not be effective for predicting EWP returns.

\section{Methodology}

We implement the low frequency momentum trading strategy using firstly the HP filter and secondly the kernel regression approach. The HP filter is implemented initially using the commonly employed 'default' smoothing parameter of 100 multiplied by the squared frequency of the data (i.e. 14,400 for the monthly data employed here), but we investigate a wide range of values for the smoothing parameter to establish the robustness of the HP filter approach. The kernel regression is implemented using four different distributions: Gaussian, parabolic, triangular and cosine. The bandwidth is initially set to a 'default' value of one quarter of the interquartile range, but again we investigate a wide range of values for the bandwidth parameter to establish the robustness of the kernel regression approach. The kernelsmoothed exchange rate is evaluated at each observation in the estimation sample, and the domain of the kernel is equal to the full estimation sample.

For both the HP filter and the kernel regression, the non-linear trend is estimated recursively, with the initial estimation undertaken using the June 1986 to May 1993 period. The estimation period is then rolled forward each month through the evaluation period June 1993 to May 2008. Like all trend smoothing filters, both the HP filter and the kernel regression tend to over-fit data at the end-points. To test these end-point effects in our analysis, we experimented with extending the data beyond the estimation sample using both trend and autoregressive forecasts, but observed no significant improvements. This could be because over-fitting the end-points may actually help in the context of momentum trading, which relies on identifying turning points in the non-linear trend. We generate buy and sell signals by applying an $\mathrm{MA}(1,2)$ rule to the estimated low frequency component, so that a buy signal is generated when the current month's low frequency trend is higher than the previous month's low frequency trend, and a sell signal is generated when it is lower. 
As a benchmark for the low frequency trading strategy, we implement the moving average rules $\operatorname{MA}(1,2), \operatorname{MA}(1,3), \operatorname{MA}(1,4), \operatorname{MA}(1,5)$ and $\operatorname{MA}(1,6), \operatorname{MA}(2,3)$, $\operatorname{MA}(2,6)$ and $\operatorname{MA}(3,6)$. Our choice of a relatively small set of rules, and in particular, a set that is limited to only those rules that have been in use in practice for a long period of time, is designed to minimise the bias that potentially arises from datasnooping (see, for example, Brock, Lakonishok and LeBaron, 1992; Neely, Weller and Dittmar, 1997). For both the MA rules and the low-frequency trading strategy, we calculate the annualised return. We ignore trading costs (which are negligible for monthly foreign exchange strategies, particularly those that are trend-following), but include carry dividends (i.e. the interest earned on the domestic or foreign currency while it is held). In addition, we report the annualised Sharpe ratio, maximum drawdown and the directional accuracy of each strategy. Maximum drawdown is defined as the largest decline from a preceding peak in the exchange rate in which the trading strategy is invested.

\section{Empirical Results}

Table 2 reports the directional accuracy (Panel A), annualised return (Panel B), Sharpe ratio (Panel C) and maximum drawdown (Panel D) for the benchmark moving average rules for the full sample. The MA rules perform best for the EUR, JPY and SEK, with directional accuracy of the order of 55 percent. They perform worst for the GBP, with directional accuracy of less than 50 percent for all but one of the rules. Although the performance of the different MA rules is far from uniform across the different currencies and different measures, the best performing single MA rule across the four measures appears to be the $\operatorname{MA}(1,2)$, which is the rule that is most commonly used in the fund management industry for monthly exchange rates. The $\mathrm{MA}(1,2)$ rule generates directional accuracy of 52.8 percent for the EWP, an annualised return of 1.91 percent, a Sharpe ratio of 0.41 and maximum drawdown of 9.6 percent. The $\mathrm{MA}(1,5)$ rule has marginally higher directional accuracy and annualised return, but a significantly lower Sharpe ratio. Of the double MA rules, the $\mathrm{MA}(2,6)$ rule appears to be the best performing, and exceeds the $\mathrm{MA}(1,2)$ rule in terms of directional accuracy, annualised return and Sharpe ratio, but has significantly higher maximum drawdown, reflecting the higher risk of double MA rules generally. 
It is interesting to note that the performance of the MA rules is very sensitive to the choice of lag parameters, and in a non-monotonic way. For example, moving from the $\mathrm{MA}(1,2)$ rule to the $\mathrm{MA}(1,3)$ rule leads to a significant deterioration in performance using all four measures for the EWP and for the majority of the individual currencies. However, the $\mathrm{MA}(1,4)$ rule generally offers slightly higher performance than the MA(1, 3) rule. Moreover, the optimal MA rule is also very much dependent on the currency. For example, in terms of the Sharpe ratio, the $\operatorname{MA}(1,2)$ rule is the best single MA rule for SEK, NOK, AUD and the EWP, but the MA(1, 3) rule appears to be optimal for CHF, CAD and NZD. Similarly, the double MA rules work well for JPY, GBP, SEK, NOK, NZD and the EWP, but the single MA rules work well for EUR, CHF, AUD and CAD. Thus, while many of the MA rules evidently generate positive excess returns, they are highly sensitive to the currency employed, the choice of MA lag length and the criterion used to judge their performance.

\section{[Table 2]}

Table 3 reports the results for the low frequency momentum trading strategy based on the HP filter, using the default smoothing parameter of 14,400 as well as values that are 10 percent and 20 percent smaller and larger than this. It is clear that the HP strategies offer a very substantial improvement over the MA strategies, across all four measures and for almost all of the currencies. For the EWP, the HP strategies offer better directional accuracy than any of the MA rules, significantly higher annualised returns and Sharpe ratios, and almost invariably lower maximum drawdown. The differences are substantial: the highest annual return for the EWP offered by the MA strategies is 2.32 percent (using the $\operatorname{MA}(2,6)$ rule), while the lowest annualised return offered by the HP strategies is 4.36 percent (using a smoothing parameter of 12,960). Owing to the relatively low risk of the HP strategies (which is evident from their lower maximum drawdown), the difference in Sharpe ratios between the HP strategies and the MA strategies is even more striking. At the individual currency level, the HP strategies outperform the MA strategies in almost all cases, with perhaps the EUR as the most notable exception.

\section{[Table 3]}


Perhaps the most striking feature of the HP strategy is its insensitivity to the choice of smoothing parameter. Figure 3 offers further evidence on this, reporting the annualised return (excluding carry interest) and Sharpe ratio for the EWP across a wider range of values for the smoothing parameter. While varying the smoothing parameter across a wider range of values clearly does to some extent affect the performance of the HP strategy, in no case does its performance fall to that of even the best performing MA rule. Moreover, the default smoothing parameter value (of 14,400) appears to be almost optimal. As the smoothing parameter approaches zero, the recovered non-linear trend converges to the original series and so the HP strategy converges to the $\mathrm{MA}(1,2)$ rule. As the smoothing parameter approaches infinity, the HP strategy converges to a linear trend, which will capture turning points in the exchange rate only with a very significant delay, particularly when the estimation sample is large.

[Figure 3]

Table 4 reports the results for the low frequency momentum trading strategy based on the Nadaraya-Watson kernel regression, using the Gaussian, parabolic, triangular and cosine distributions. The bandwidth parameter, $h$, is initially set to the default value of one-quarter of the inter-quartile range for each series. Like the HP strategy, the kernel strategy uniformly outperforms the MA strategy across all four measures and for most currencies. The Gaussian kernel generates somewhat worse performance than the parabolic, triangular and cosine kernels. With the exception of the Gaussian kernel, the kernel strategy offers marginally better performance than the HP strategy. For example, for the EWP, the parabolic kernel strategy yields directional accuracy of 62.8 percent, an annualised return of 4.62 percent and a Sharpe ratio of 0.80 , compared to 60.6 percent, 4.49 percent and 0.76, respectively, for the HP strategy with a smoothing parameter of 14,400. The Gaussian kernel underperforms for the EWP, and for the majority of individual currencies (particularly JPY and AUD) but interestingly offers better performance than the parabolic, triangular and cosine kernels for the NOK and CAD.

[Table 4] 
Figure 4 plots the annualised return (excluding carry interest) and Sharpe ratio for the low frequency momentum trading strategy based on the parabolic kernel regression for a range of values of the bandwidth parameter, $h$, for the EWP. Again, the performance of the kernel strategy is relatively robust across a wide range of values for the smoothing parameter, although for extreme (small and large) values, there is significant deterioration in performance. Moreover, the default bandwidth value of one quarter of the inter-quartile range appears to yield almost optimal performance.

\section{[Figure 4]}

To further investigate the properties of the low frequency momentum approach, Figure 5 plots the out-of-sample forecasts of the USD/JPY exchange rate for the HP filter (using the default smoothing parameter of 14,400) and the kernel regression (using the default bandwidth value, and averaged across the four distributions) against the actual USD/JPY exchange rate. Clearly, the two non-parametric filters capture the prolonged trends that arise from the cyclical component of the exchange rate, which accounts for the success of the trading strategies based on these filters. Note, however, that both filters are generally late in capturing the turning points of the non-linear trend because they are being used to forecast the trend out-of-sample (in contrast with the in-sample illustration in Figure 2), and turning points in the long run trend can only be recognised as such once they have occurred. Nevertheless, both the HodrickPrescott filter and the kernel regression are evidently effective tools for forecasting the dynamics of the exchange rate out-of-sample.

\section{[Figure 5]}

To investigate the temporal stability of the various strategies, Tables 5-7 report fiveyear sub-sample results for the $\mathrm{MA}(1,2)$ rule, the HP filter with a smoothing parameter of 14,400 and the parabolic kernel regression with the default bandwidth parameter. For all three strategies, there is considerable variation in performance over time. The MA strategy generally worked best during the 1998-2003 period, offering both higher returns and lower risk. For example, the annualised return for the EWP is 4.41 percent during the $1998-2003$ period, 1.48 percent during the 1993-1998 period 
and -0.17 percent during the 2003-2008 period. However, this is not uniform across currencies, and in several cases, the highest annualised returns were generated during 2003-2008. On balance, however, it appears that the success of the $\operatorname{MA}(1,2)$ strategy has diminished over time, perhaps reflecting its increasingly widespread use in the foreign exchange market.

In contrast with the MA strategy, however, there is less evidence that the performance of either the HP strategy or the kernel strategy has diminished over time. Indeed, for the EWP (and for many of the individual currencies), the annualised return of the HP strategy has increased over time, although there is evidence that the strategy has become riskier, with higher maximum drawdown and lower Sharpe ratios in the first two sub-samples than in the third. However, the broad conclusion is that the low frequency momentum trading strategies based on the HP filter and kernel regression display substantially greater temporal stability than do MA trading strategies.

\section{[Tables 5-7]}

\section{Conclusion}

Momentum in spot exchange rates has been widely exploited in trading strategies used by currency fund managers and commodity trading advisors. The single most important momentum trading strategy in the foreign exchange market is the moving average (MA) rule, in which buy and sell signals are generated by the intersection of averages of the current and lagged spot exchange rate over different horizons. The success of momentum trading strategies hinges on the extraction of a non-linear trend forecast from the spot exchange rate. While undoubtedly successful in terms of generating excess returns relative to a buy-and-hold strategy, the success of such MA rules is limited by the presence of a substantial 'noise' component in the spot exchange rate, which makes identification of any trend particularly difficult.

In this paper, we take an alternative, more rigorous approach to the identification of the non-linear trend in the spot exchange rate. In particular, we develop a low frequency momentum trading strategy that is based on a decomposition of the spot exchange rate into its regular and irregular components. We use short-term 
momentum in the low frequency trend component to generate directional forecasts of the spot exchange rate. In order to decompose the spot exchange rate into its regular and irregular components, we employ, alternately, the high-pass filter of Hodrick and Prescott (1997) and the Nadaraya-Watson kernel regression.

We apply the low frequency trading strategy to individual G10 ex-USD currencies, and to an equally weighted portfolio of these currencies, using monthly data over the period 1993-2008. We calculate the out-of-sample performance of the trading strategy both over the full sample, and over three sub-samples. As a benchmark, we compare the low frequency momentum trading strategy to strategies that are based on a range of single and double MA rules, including those that are widely used in practice. We find that the low frequency momentum trading strategy generates significantly higher returns and Sharpe ratios than those based on traditional MA rules, as well as lower maximum drawdown and greater directional accuracy. Unlike the MA rules, the performance of the low frequency momentum trading strategy is relatively stable over different sample periods. Importantly, the low frequency momentum trading strategy is robust to the choice of smoothing parameter (in the case of the HP filter) and the distribution and bandwidth parameter (in the case of kernel regression) over a wide range of values.

The results reported in this paper generate some interesting questions for future research. The trading strategy proposed in this paper exploits short term momentum in the non-linear trend component of the exchange rate (rather than in the exchange rate itself), and uses the most rudimentary approach - the $\operatorname{MA}(1,2)$ rule - to measure this momentum. A natural line of future enquiry would be to investigate alternative technical trading strategies that are based on the non-linear trend, for example more sophisticated MA rules or filter rules. Alternatively, it might be productive to investigate combining trading strategies based on the non-linear trend with traditional technical trading rules, on the basis that both are successful, but each may be capturing a different aspect of exchange rate dynamics. Finally, another natural line of research would be to investigate the performance of low frequency momentum trading strategies using higher frequency data. 


\section{References}

Baxter, M., and R. King, 1999, "Measuring Business Cycles: Approximate Band-Pass Filters for Economic Time Series”, Review of Economics and Statistics 81, 575-593.

Brock, W., J. Lakonishok and B. LeBaron, 1992, "Simple Technical Trading Rules and the Stochastic Properties of Stock Returns”, Journal of Finance 47, 1731-64.

Chan, K., N. Jegadeesh and J. Lakonishok, 1996, “Momentum Strategies”, Journal of Finance 51, 1681-1713.

Chan, K., A. Hameed and W. Tong, 2000, "Profitability of momentum strategies in the international equity markets”, Journal of Financial and Quantitative Analysis 35, 153-172.

Christiano, L., and T. Fitzgerald, 2003, “The Band Pass Filter”, International Economic Review 44, 435-465.

Christoffersen, P., and F. Diebold, 2006, "Financial Asset Returns, Direction-ofChange Forecasting, and Volatility Dynamics”, Management Science 52, 1273-1287.

Christoffersen, P., F. Diebold, R. Mariano, A. Tay and Y. Tse, 2007, "Direction-ofChange Forecasts Based on Conditional Variance, Skewness and Kurtosis Dynamics: International Evidence”, Journal of Financial Forecasting 1, 3-24.

Ehlgen, J., 1998, "Distortionary Effects of the Optimal Hodrick-Prescott Filters", Economics Letters 61, 345-349.

Hodrick, R., and E. Prescott, 1997, "Post-war Business U.S. Cycles: An Empirical Investigation”, Journal of Money, Credit and Banking 29, 1-16.

Jegadeesh, N., and S. Titman, 1993, "Returns to Buying Winners and Selling Losers: Implications for Stock Market Efficiency”, Journal of Finance 58, 65-91.

Jegadessh, N., and S. Titman, 2001, "Profitability of Momentum Strategies: An Evaluation of Alternative Explanations”, Journal of Finance 56.

Korajczyk. R., and R. Sadka, 2004, “Are Momentum Profits Robust to Trading Costs?", Journal of Finance 59, 1039-1082.

Kritzman, M., 1989, "Serial Dependence in Currency Returns: Investment Implications”, Journal of Portfolio Management 16, 96-102.

Kho, B., 1996, “Time-varying risk premia, volatility, and technical trading rule profits: Evidence from foreign currency futures markets", Journal of Financial Economics 41, 249-90.

LeBaron, B., 1999, “Technical Trading Rule Profitability and Foreign Exchange Intervention”, Journal of International Economics 49, 125-143. 
Levich R., 1985, "Empirical studies of Exchange Rates: Price Behaviour, Rate Determination and Market Efficiency", in R. Jones and P. Kenen: Handbook of International Economics 2, 980-1036.

Levich, R., 1989, “Is the Foreign Exchange Market Efficient?” Oxford Review of Economic Policy 5, 40-60.

Levich, R. and L. Thomas, 1993, “The Significance of Technical Trading-rule Profits in the Foreign Exchange Market: a Bootstrap Approach”, Journal of International Money and Finance 12, 451-474.

Neely, C., 1997, "Technical analysis in the foreign exchange market: a layman's guide”, Federal Reserve Bank of St. Louis Review 79, 23-38.

Neely, C., P. Weller and R. Ditmar, 1997, “Is Technical Analysis Profitable in Foreign Exchange Markets? A Genetic Programming Approach”, Journal of Financial and Quantitative Analysis 32, 405-426.

Okunev, J., and D. White, 2003, "Do Momentum-Based Strategies Still Work in Foreign Currency Markets”, Journal of Financial and Quantitative Analysis 38, 425447.

Olson, D., 2004, "Have trading rule profits in the currency market declined over time?”, Journal of Banking and Finance 28, 85-105.

Rouwenhorst, K., 1998, “International Momentum Strategies,” Journal of Finance 53, 267-284.

Sweeney, R., 1986, “Beating the Foreign Exchange Market”, Journal of Finance 41, 163-182.

Szakmary, A., and I. Mathur, 1997, "Central Bank Intervention and Trading Rule Profits in Foreign Exchange Markets”, Journal of International Money and Finance, 513-35.

Taylor, S., 1992, "Efficiency in the Yen Futures Market at the Chicago Mercantile Exchange”, in Rational Expectations and Efficiency in Futures Markets. Routledge.

Taylor, S., 1994, “Trading Futures Using a Channel Rule: A Study of Predictive Power of Technical Analysis with Currency Examples”, Journal of Futures Markets $14,215-235$.

Taylor, M., 1992, “The use of Technical Analysis in the Foreign Exchange Market”, Journal of International Money and Finance 11, 304-314.

Wand, M., and M. Jones, 1995, Kernel Smoothing, Chapman and Hall, London. 
Figure 1 Decomposition of USD/JPY into Trend, Cycle and Irregular Components

\section{Panel A: Trend}

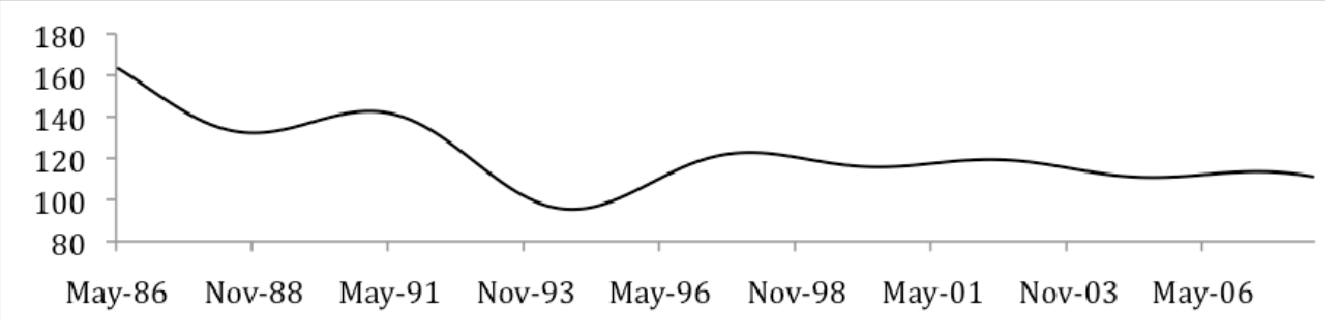

\section{Panel B: Cycle}

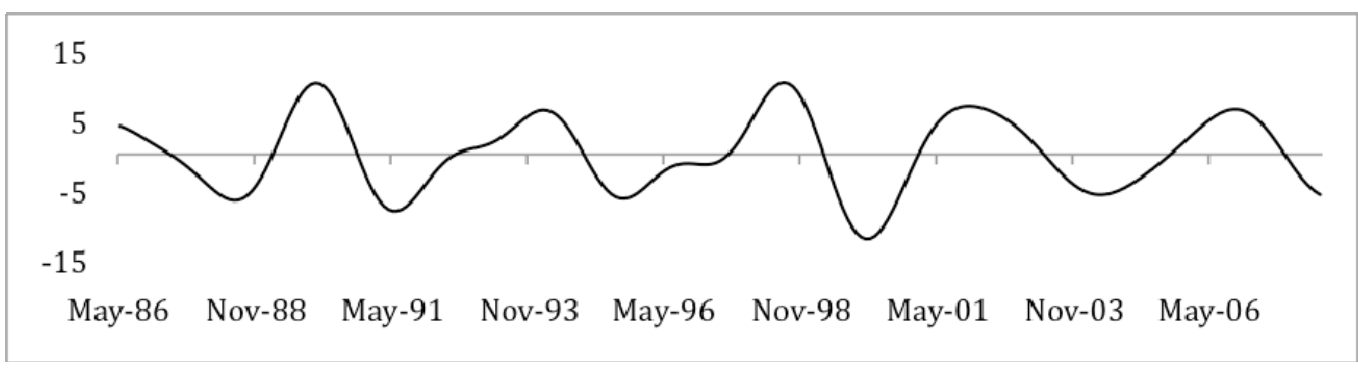

Panel C: Irregular Component

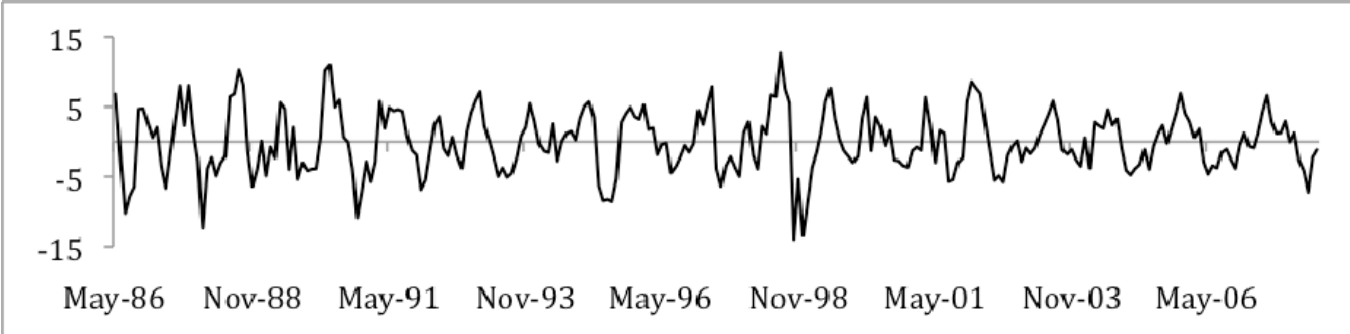

Notes: The figure shows the decomposition of the monthly USD/JPY spot exchange rate over the period June 1986 to May 2008 into trend (Panel A), cycle (Panel B) and the irregular component (Panel C) using the Christiano and Fitzgerald (2003) bandpass filter. 
Figure 2 USD/JPY versus Trend plus Cycle Components

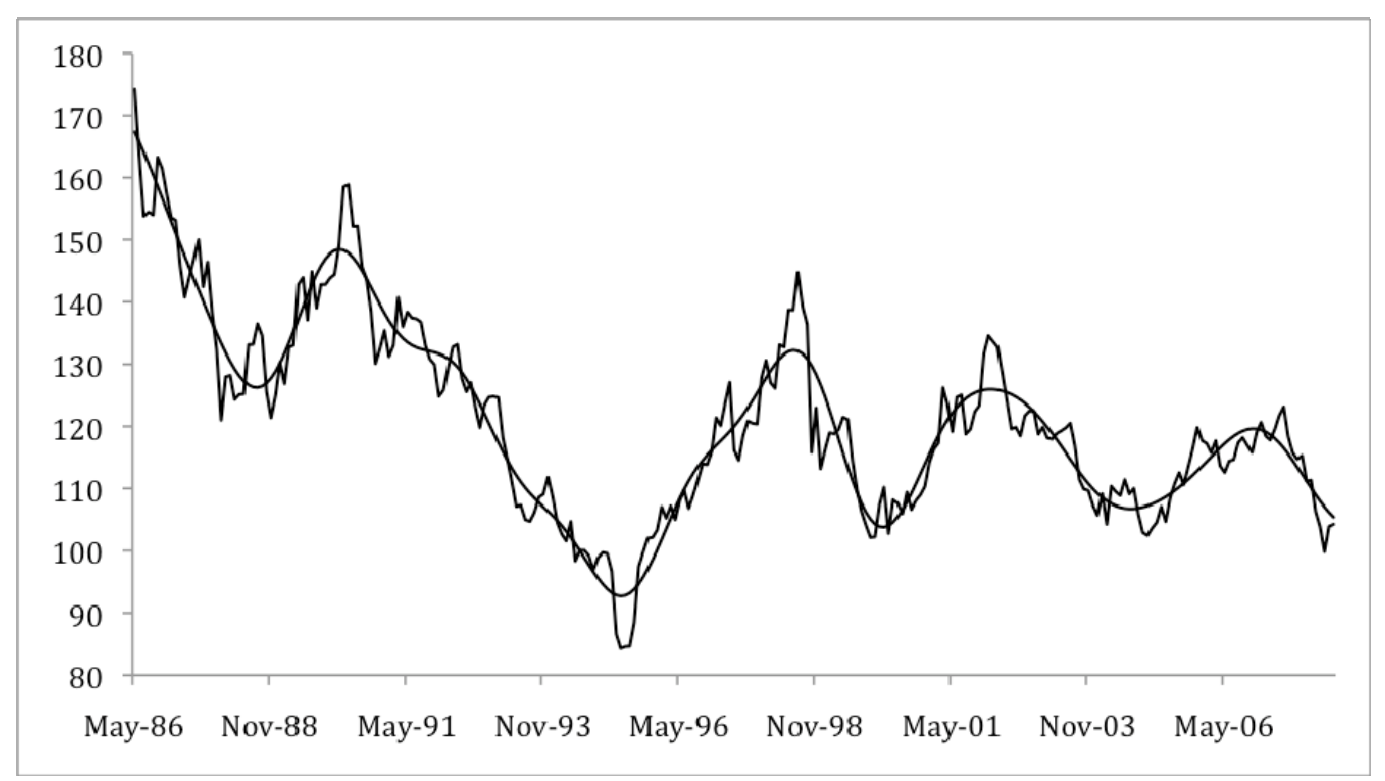

Notes: The figure shows the USD/JPY spot exchange rate over the period June 1986 to May 2008 and the trend plus cycle components from the Christiano and Fitzgerald (2003) bandpass filter. 


\section{Panel A: Return}

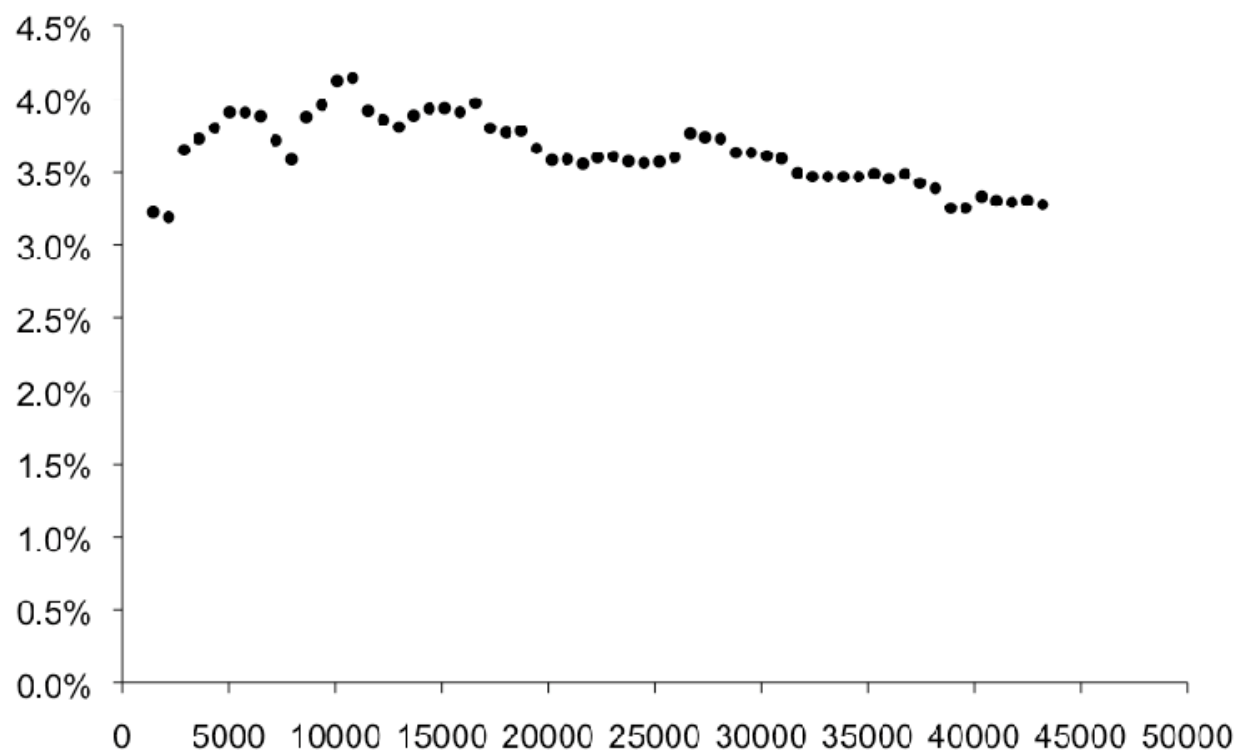

Panel B: Sharpe Ratio

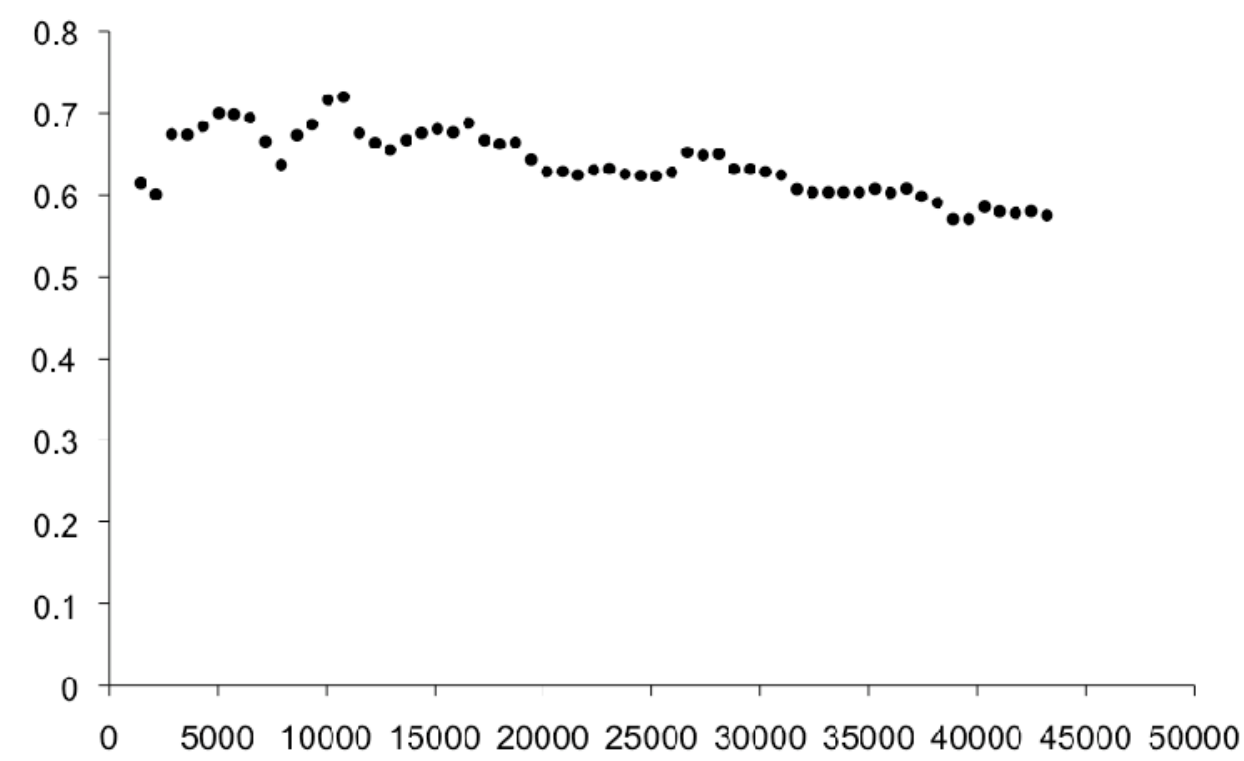

Notes: The figure shows the return (Panel A) and Sharpe ratio (Panel B) of the EWP momentum trading strategy using the Hodrick-Prescott filter for different values of the smoothing parameter, $\lambda$. 


\section{Panel A: Return}

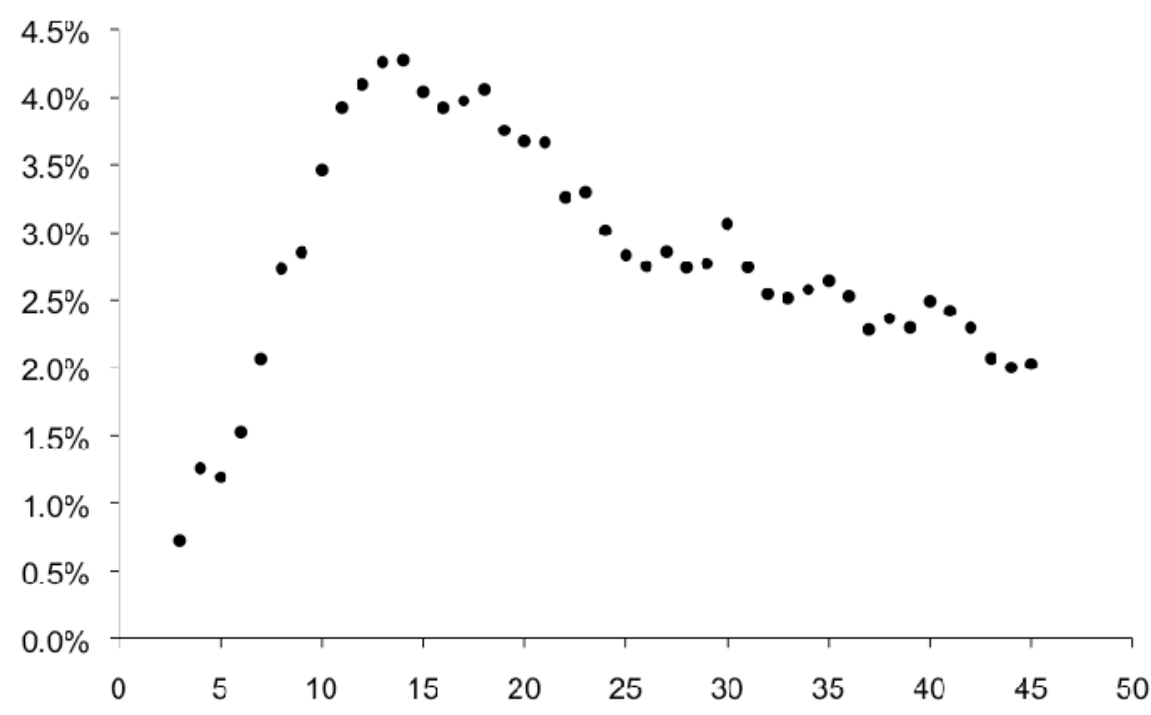

Panel B: Sharpe Ratio

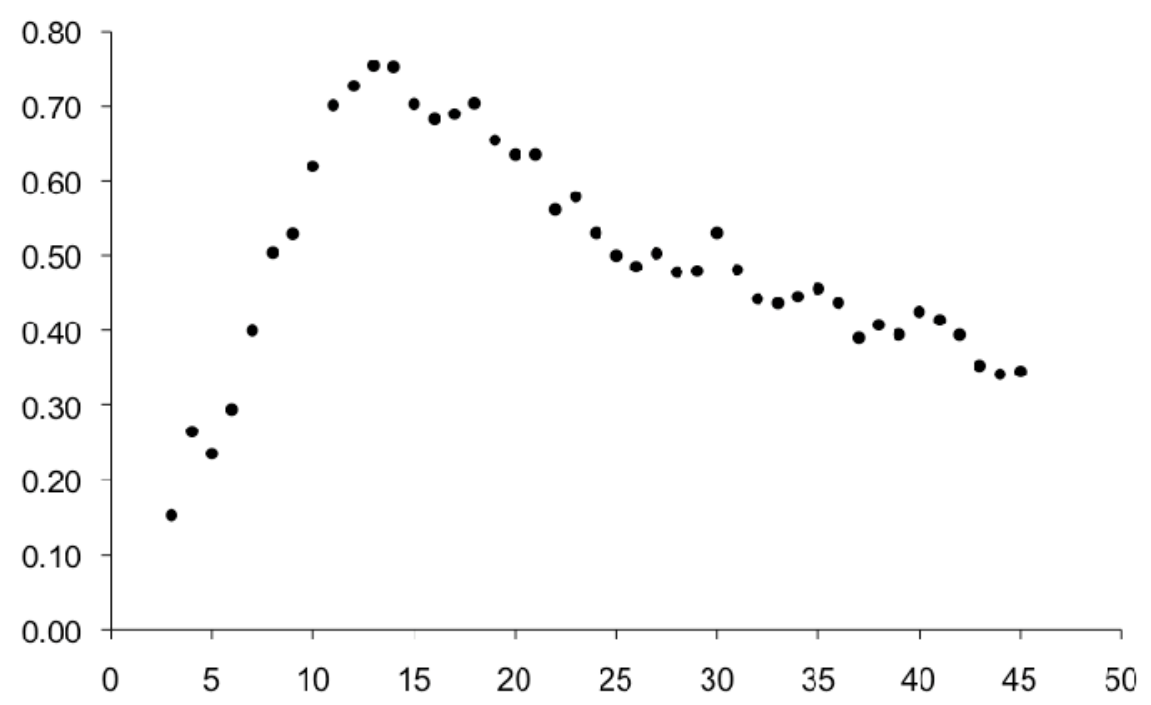

Notes: The figure shows the return (Panel A) and Sharpe ratio (Panel B) of the EWP momentum trading strategy using the kernel regression with a parabolic distribution for different values of the bandwidth parameter, $h$. 


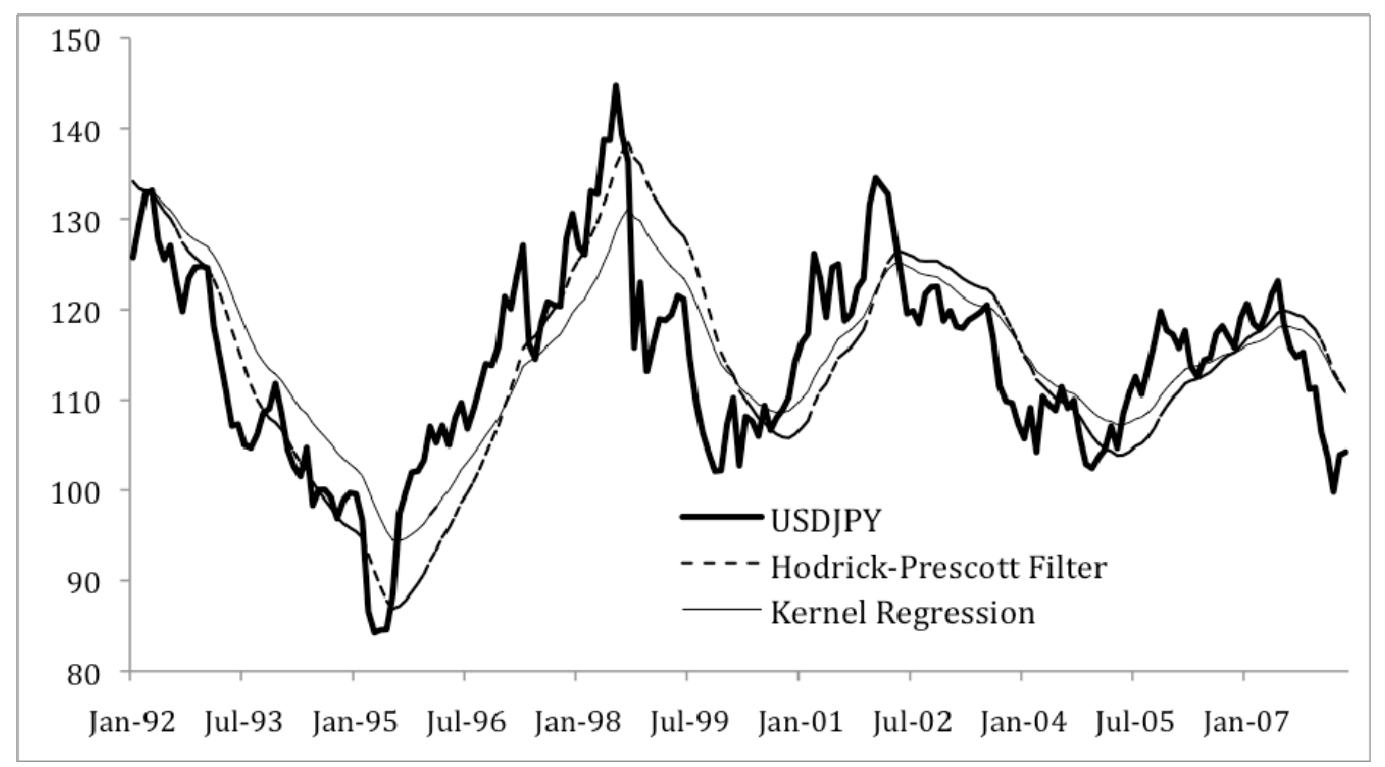

Notes: The figure shows the out-of-sample forecasts of the non-linear trend for the USD/JPY exchange rate over the period June 1993 to May 2008 using the Hodrick-Prescott filter with a smoothing parameter of 14,400 and the average of the four kernel regressions with the default bandwidth value. 
Table 1 Summary Statistics

Panel A: Summary Statistics

$\begin{array}{ccccccccccc} & \text { EUR } & \text { JPY } & \text { GBP } & \text { CHF } & \text { SEK } & \text { NOK } & \text { AUD } & \text { CAD } & \text { NZD } & \text { EWP } \\ \text { Mean } & 0.30 \% & 0.12 \% & 0.34 \% & -0.04 \% & 0.38 \% & -0.17 \% & -0.17 \% & -0.32 \% & 0.49 \% & 0.10 \% \\ \text { SD } & 2.85 \% & 3.32 \% & 2.76 \% & 3.23 \% & 2.95 \% & 1.74 \% & 3.10 \% & 2.90 \% & 2.95 \% & 0.79 \% \\ \text { Skewness } & -0.155 & -0.320 & -0.480 & 0.195 & -0.342 & 0.164 & 0.719 & 0.426 & -0.155 & -0.325 \\ \text { Kurtosis } & 0.209 & 1.398 & 2.028 & -0.029 & 0.566 & 0.958 & 2.482 & 1.022 & 0.885 & 1.324 \\ \text { Jarque-Bera } & 1.135 & 172.579 & 754.870 & 1.671 & 9.657 & 38.292 & 1691.795 & 55.923 & 28.033 & 139.835 \\ & {[0.567]} & {[0.000]} & {[0.000]} & {[0.434]} & {[0.008]} & {[0.000]} & {[0.000]} & {[0.000]} & {[0.000]} & {[0.000]}\end{array}$

Panel B: Autocorrelations

$\begin{array}{ccccccccccc} & \text { EUR } & \text { JPY } & \text { GBP } & \text { CHF } & \text { SEK } & \text { NOK } & \text { AUD } & \text { CAD } & \text { NZD } & \text { EWP } \\ \mathbf{1} & 0.153 & 0.018 & 0.096 & 0.138 & 0.009 & 0.027 & 0.178 & 0.084 & 0.038 & 0.013 \\ & {[0.012]} & {[0.763]} & {[0.117]} & {[0.024]} & {[0.883]} & {[0.655]} & {[0.004]} & {[0.170]} & {[0.534]} & {[0.835]} \\ \mathbf{2} & -0.001 & 0.089 & -0.091 & 0.001 & -0.065 & -0.041 & -0.031 & -0.005 & -0.013 & 0.019 \\ & {[0.988]} & {[0.147]} & {[0.135]} & {[0.992]} & {[0.289]} & {[0.500]} & {[0.607]} & {[0.933]} & {[0.830]} & {[0.761]} \\ \mathbf{3} & 0.003 & 0.023 & 0.020 & -0.002 & 0.121 & -0.028 & 0.046 & 0.021 & 0.175 & -0.097 \\ & {[0.957]} & {[0.702]} & {[0.746]} & {[0.968]} & {[0.047]} & {[0.647]} & {[0.454]} & {[0.733]} & {[0.004]} & {[0.113]} \\ \mathbf{4} & -0.084 & -0.013 & -0.032 & -0.074 & 0.004 & 0.103 & -0.036 & -0.097 & 0.015 & -0.053 \\ & {[0.167]} & {[0.833]} & {[0.597]} & {[0.222]} & {[0.954]} & {[0.090]} & {[0.558]} & {[0.110]} & {[0.806]} & {[0.383]} \\ \mathbf{5} & -0.027 & -0.114 & -0.053 & -0.045 & -0.002 & -0.010 & -0.022 & -0.028 & 0.074 & -0.052 \\ & {[0.652]} & {[0.061]} & {[0.385]} & {[0.457]} & {[0.969]} & {[0.868]} & {[0.717]} & {[0.649]} & {[0.222]} & {[0.390]} \\ \mathbf{6} & -0.058 & -0.099 & -0.073 & -0.080 & 0.123 & -0.057 & -0.048 & 0.025 & 0.077 & -0.091 \\ & {[0.336]} & {[0.102]} & {[0.230]} & {[0.185]} & {[0.043]} & {[0.348]} & {[0.427]} & {[0.679]} & {[0.203]} & {[0.134]}\end{array}$

Notes: The table reports summary statistics for the monthly G10 exchange rates over the period June 1986 to May 2008, and for an equally weighted portfolio (EWP) of the G10 currencies. $\rho_{k}$ is the $k$ th order autocorrelation coefficient. For the Jarque-Bera statistic and the autocorrelation coefficients, p-values are reported in parentheses. 
Table 2 Trading Strategy Peformance (Moving Average)

Panel A: Directional Accuracy

$\begin{array}{lcccccccccc} & \text { EUR } & \text { JPY } & \text { GBP } & \text { CHF } & \text { SEK } & \text { NOK } & \text { AUD } & \text { CAD } & \text { NZD } & \text { EWP } \\ \text { MA(1, 2) } & 54.4 \% & 56.7 \% & 41.7 \% & 51.7 \% & 53.3 \% & 50.0 \% & 52.2 \% & 47.8 \% & 51.1 \% & 52.8 \% \\ \text { MA(1, 3) } & 51.7 \% & 57.8 \% & 40.6 \% & 46.1 \% & 53.9 \% & 47.2 \% & 46.7 \% & 48.3 \% & 51.1 \% & 51.7 \% \\ \text { MA(1, 4) } & 51.1 \% & 55.6 \% & 41.1 \% & 48.3 \% & 51.7 \% & 46.7 \% & 48.3 \% & 48.9 \% & 56.1 \% & 51.1 \% \\ \text { MA(1, 5) } & 52.8 \% & 53.3 \% & 42.2 \% & 46.7 \% & 56.1 \% & 47.2 \% & 46.7 \% & 50.0 \% & 56.7 \% & 53.3 \% \\ \text { MA(1, 6) } & 51.7 \% & 51.7 \% & 43.3 \% & 45.0 \% & 57.2 \% & 46.7 \% & 48.3 \% & 51.7 \% & 58.3 \% & 51.7 \% \\ \text { MA(2, 3) } & 46.7 \% & 55.0 \% & 44.4 \% & 46.1 \% & 50.0 \% & 51.7 \% & 47.2 \% & 45.0 \% & 50.0 \% & 46.1 \% \\ \text { MA(2, 6) } & 53.3 \% & 53.3 \% & 47.8 \% & 45.0 \% & 59.4 \% & 53.3 \% & 51.7 \% & 50.6 \% & 58.9 \% & 55.6 \% \\ \text { MA(3, 6) } & 51.1 \% & 50.0 \% & 52.8 \% & 48.3 \% & 61.1 \% & 50.6 \% & 53.3 \% & 50.0 \% & 63.3 \% & 55.0 \%\end{array}$

\section{Panel B: Return}

$\begin{array}{lcccccccccc} & \text { EUR } & \text { JPY } & \text { GBP } & \text { CHF } & \text { SEK } & \text { NOK } & \text { AUD } & \text { CAD } & \text { NZD } & \text { EWP } \\ \text { MA(1, 2) } & 6.14 \% & 0.67 \% & -2.80 \% & 1.54 \% & 2.43 \% & 0.90 \% & 3.32 \% & 0.58 \% & 4.38 \% & 1.91 \% \\ \text { MA(1, 3) } & 6.24 \% & 2.62 \% & -3.39 \% & 0.12 \% & 2.38 \% & -0.37 \% & -0.21 \% & 0.86 \% & 3.74 \% & 1.33 \% \\ \text { MA(1, 4) } & 4.39 \% & 2.55 \% & -3.26 \% & 1.59 \% & -0.31 \% & -0.89 \% & -0.28 \% & 1.51 \% & 6.57 \% & 1.32 \% \\ \text { MA(1, 5) } & 4.93 \% & 2.48 \% & -2.43 \% & 1.24 \% & 1.76 \% & -0.81 \% & -1.37 \% & 1.26 \% & 5.07 \% & 1.35 \% \\ \text { MA(1, 6) } & 3.63 \% & 2.91 \% & -2.43 \% & -0.65 \% & 2.75 \% & -0.86 \% & -0.47 \% & 2.49 \% & 5.58 \% & 1.44 \% \\ \text { MA(2, 3) } & 2.50 \% & 4.27 \% & -2.97 \% & -1.22 \% & -1.22 \% & 0.87 \% & -2.11 \% & 0.41 \% & 0.54 \% & 0.12 \% \\ \text { MA(2, 6) } & 3.41 \% & 4.74 \% & 0.13 \% & -1.39 \% & 4.30 \% & 2.55 \% & 0.92 \% & 0.90 \% & 5.33 \% & 2.32 \% \\ \text { MA(3, 6) } & 1.53 \% & -0.34 \% & 1.01 \% & 0.16 \% & 6.07 \% & 1.11 \% & 2.67 \% & -1.31 \% & 7.94 \% & 2.09 \%\end{array}$

\section{Panel C: Sharpe Ratio}

$\begin{array}{lcccccccccc} & \text { EUR } & \text { JPY } & \text { GBP } & \text { CHF } & \text { SEK } & \text { NOK } & \text { AUD } & \text { CAD } & \text { NZD } & \text { EWP } \\ \text { MA(1, 2) } & 0.71 & 0.06 & -0.39 & 0.15 & 0.24 & 0.14 & 0.33 & 0.06 & 0.44 & 0.41 \\ \text { MA(1, 3) } & 0.72 & 0.23 & -0.47 & 0.01 & 0.23 & -0.06 & -0.02 & 0.09 & 0.37 & 0.27 \\ \text { MA(1, 4) } & 0.50 & 0.23 & -0.46 & 0.16 & -0.03 & -0.13 & -0.03 & 0.16 & 0.66 & 0.28 \\ \text { MA(1, 5) } & 0.56 & 0.22 & -0.34 & 0.12 & 0.17 & -0.12 & -0.14 & 0.13 & 0.51 & 0.28 \\ \text { MA(1, 6) } & 0.41 & 0.26 & -0.34 & -0.06 & 0.27 & -0.13 & -0.05 & 0.26 & 0.56 & 0.29 \\ \text { MA(2, 3) } & 0.28 & 0.38 & -0.42 & -0.12 & -0.12 & 0.13 & -0.21 & 0.04 & 0.05 & 0.02 \\ \text { MA(2, 6) } & 0.39 & 0.43 & 0.02 & -0.14 & 0.43 & 0.39 & 0.09 & 0.09 & 0.53 & 0.45 \\ \text { MA(3, 6) } & 0.17 & -0.03 & 0.14 & 0.02 & 0.61 & 0.17 & 0.27 & -0.14 & 0.81 & 0.40\end{array}$

\section{Panel D: Maximum Drawdown}

$\begin{array}{lcccccccccc} & \text { EUR } & \text { JPY } & \text { GBP } & \text { CHF } & \text { SEK } & \text { NOK } & \text { AUD } & \text { CAD } & \text { NZD } & \text { EWP } \\ \text { MA(1, 2) } & 18.1 \% & 37.8 \% & 50.8 \% & 32.2 \% & 37.8 \% & 20.7 \% & 17.3 \% & 33.1 \% & 19.4 \% & 9.6 \% \\ \text { MA(1, 3) } & 15.9 \% & 23.6 \% & 51.7 \% & 38.9 \% & 32.1 \% & 20.7 \% & 29.1 \% & 29.1 \% & 24.9 \% & 11.5 \% \\ \text { MA(1, 4) } & 18.9 \% & 25.2 \% & 48.9 \% & 34.4 \% & 41.0 \% & 27.9 \% & 29.7 \% & 23.3 \% & 16.8 \% & 8.2 \% \\ \text { MA(1, 5) } & 18.9 \% & 24.8 \% & 42.8 \% & 18.2 \% & 26.6 \% & 26.6 \% & 47.8 \% & 26.0 \% & 28.2 \% & 10.0 \% \\ \text { MA(1, 6) } & 25.7 \% & 30.9 \% & 45.3 \% & 26.5 \% & 26.8 \% & 27.7 \% & 36.9 \% & 26.1 \% & 29.1 \% & 13.3 \% \\ \text { MA(2, 3) } & 19.1 \% & 22.5 \% & 48.1 \% & 30.5 \% & 44.1 \% & 24.2 \% & 37.9 \% & 25.3 \% & 40.4 \% & 14.2 \% \\ \text { MA(2, 6) } & 23.3 \% & 16.7 \% & 23.2 \% & 44.5 \% & 32.1 \% & 10.7 \% & 26.4 \% & 33.8 \% & 39.7 \% & 16.2 \% \\ \text { MA(3, 6) } & 25.6 \% & 40.3 \% & 25.8 \% & 34.1 \% & 18.8 \% & 23.7 \% & 31.0 \% & 51.8 \% & 32.8 \% & 15.3 \%\end{array}$

Notes: The table reports the directional accuracy, annualised return, annualised Sharpe ratio and maximum drawdown for the momentum trading strategy based on the $\mathrm{MA}(\mathrm{m}, \mathrm{n})$ rule. Results are reported for the G10 currencies and the equally weighted portfolio (EWP). The evaluation period is June 1993 to May 2008. 
Table 3 Trading Strategy Peformance (Hodrick-Prescott Filter)

\section{Panel A: Directional Accuracy}

$\begin{array}{lcccccccccc} & \text { EUR } & \text { JPY } & \text { GBP } & \text { CHF } & \text { SEK } & \text { NOK } & \text { AUD } & \text { CAD } & \text { NZD } & \text { EWP } \\ \mathbf{1 1 , 5 2 0} & 55.6 \% & 53.3 \% & 57.8 \% & 51.1 \% & 60.0 \% & 53.3 \% & 55.0 \% & 53.3 \% & 61.1 \% & 61.1 \% \\ \mathbf{1 2 , 9 6 0} & 56.7 \% & 53.3 \% & 57.8 \% & 51.1 \% & 58.3 \% & 53.9 \% & 55.0 \% & 53.3 \% & 61.1 \% & 60.0 \% \\ \mathbf{1 4 , 4 0 0} & 56.1 \% & 53.9 \% & 57.8 \% & 51.1 \% & 58.9 \% & 54.4 \% & 55.0 \% & 53.9 \% & 61.7 \% & 60.6 \% \\ \mathbf{1 5 , 8 4 0} & 56.1 \% & 53.3 \% & 57.8 \% & 51.7 \% & 58.9 \% & 53.9 \% & 54.4 \% & 55.0 \% & 62.2 \% & 60.0 \% \\ \mathbf{1 7 , 8 2 0} & 55.6 \% & 53.3 \% & 57.8 \% & 51.7 \% & 59.4 \% & 53.9 \% & 55.0 \% & 55.0 \% & 61.1 \% & 60.6 \%\end{array}$

\section{Panel B: Return}

$\begin{array}{lllllllllll} & \text { EUR } & \text { JPY } & \text { GBP } & \text { CHF } & \text { SEK } & \text { NOK } & \text { AUD } & \text { CAD } & \text { NZD } & \text { EWP } \\ \mathbf{1 1 , 5 2 0} & 5.15 \% & 4.35 \% & 2.48 \% & 3.35 \% & 5.57 \% & 1.44 \% & 6.20 \% & 3.09 \% & 8.61 \% & 4.47 \% \\ \mathbf{1 2 , 9 6 0} & 5.25 \% & 4.35 \% & 2.48 \% & 3.09 \% & 4.65 \% & 1.49 \% & 6.20 \% & 3.09 \% & 8.61 \% & 4.36 \% \\ \mathbf{1 4 , 4 0 0} & 5.14 \% & 4.37 \% & 2.33 \% & 3.09 \% & 4.73 \% & 1.71 \% & 6.20 \% & 3.64 \% & 9.20 \% & 4.49 \% \\ \mathbf{1 5 , 8 4 0} & 5.14 \% & 3.97 \% & 2.33 \% & 3.38 \% & 4.46 \% & 1.42 \% & 6.04 \% & 4.25 \% & 9.38 \% & 4.49 \% \\ \mathbf{1 7 , 8 2 0} & 4.57 \% & 3.97 \% & 2.33 \% & 3.38 \% & 4.85 \% & 1.35 \% & 6.67 \% & 4.37 \% & 7.81 \% & 4.37 \%\end{array}$

Panel C: Sharpe Ratio

$\begin{array}{lcccccccccc} & \text { EUR } & \text { JPY } & \text { GBP } & \text { CHF } & \text { SEK } & \text { NOK } & \text { AUD } & \text { CAD } & \text { NZD } & \text { EWP } \\ \mathbf{1 1 , 5 2 0} & 0.59 & 0.39 & 0.35 & 0.33 & 0.56 & 0.22 & 0.63 & 0.32 & 0.88 & 0.76 \\ \mathbf{1 2 , 9 6 0} & 0.60 & 0.39 & 0.35 & 0.31 & 0.46 & 0.22 & 0.63 & 0.32 & 0.88 & 0.74 \\ \mathbf{1 4 , 4 0 0} & 0.59 & 0.39 & 0.32 & 0.31 & 0.47 & 0.26 & 0.63 & 0.38 & 0.94 & 0.76 \\ \mathbf{1 5 , 8 4 0} & 0.59 & 0.36 & 0.32 & 0.34 & 0.44 & 0.21 & 0.61 & 0.45 & 0.96 & 0.77 \\ \mathbf{1 7 , 8 2 0} & 0.52 & 0.36 & 0.32 & 0.34 & 0.48 & 0.20 & 0.68 & 0.46 & 0.79 & 0.76\end{array}$

Panel D: Maximum Drawdown

$\begin{array}{lcccccccccc} & \text { EUR } & \text { JPY } & \text { GBP } & \text { CHF } & \text { SEK } & \text { NOK } & \text { AUD } & \text { CAD } & \text { NZD } & \text { EWP } \\ \mathbf{1 1 , 5 2 0} & 15.6 \% & 32.5 \% & 16.2 \% & 23.7 \% & 22.2 \% & 31.0 \% & 15.5 \% & 32.3 \% & 24.3 \% & 8.7 \% \\ \mathbf{1 2 , 9 6 0} & 15.6 \% & 32.5 \% & 16.2 \% & 23.7 \% & 32.8 \% & 30.2 \% & 15.5 \% & 32.3 \% & 24.3 \% & 8.1 \% \\ \mathbf{1 4 , 4 0 0} & 16.5 \% & 32.5 \% & 17.9 \% & 23.7 \% & 31.6 \% & 26.8 \% & 15.5 \% & 32.3 \% & 24.3 \% & 7.7 \% \\ \mathbf{1 5 , 8 4 0} & 16.5 \% & 32.5 \% & 17.9 \% & 22.0 \% & 37.6 \% & 26.8 \% & 15.5 \% & 32.3 \% & 24.3 \% & 7.5 \% \\ \mathbf{1 7 , 8 2 0} & 16.5 \% & 32.5 \% & 17.9 \% & 22.0 \% & 34.7 \% & 26.8 \% & 15.5 \% & 28.9 \% & 24.3 \% & 7.1 \%\end{array}$

Notes: The table reports the directional accuracy, annualised return, annualised Sharpe ratio and maximum drawdown for the momentum trading strategy based on the Hodrick-Prescott filter for different values of the smoothing parameter, $\lambda$. Results are reported for the G10 currencies and the equally weighted portfolio (EWP). The Hodrick-Prescott filter is initially estimated using the sample June 1986 to May 1993. Trading signals are then generated recursively for the period June 1993 to May 2008, by applying an MA(1, 2) trading rule to the estimated non-linear trend. 
Table 4 Trading Strategy Peformance (Nadaraya-Watson Kernel Regression)

\section{Panel A: Directional Accuracy}

$\begin{array}{lcccccccccc} & \text { EUR } & \text { JPY } & \text { GBP } & \text { CHF } & \text { SEK } & \text { NOK } & \text { AUD } & \text { CAD } & \text { NZD } & \text { EWP } \\ \text { Gaussian } & 56.7 \% & 48.9 \% & 54.4 \% & 51.7 \% & 56.1 \% & 57.2 \% & 53.3 \% & 53.9 \% & 58.3 \% & 57.8 \% \\ \text { Parabolic } & 56.7 \% & 53.9 \% & 53.9 \% & 53.9 \% & 59.4 \% & 52.2 \% & 55.6 \% & 58.3 \% & 60.0 \% & 62.8 \% \\ \text { Triangular } & 58.3 \% & 53.9 \% & 50.6 \% & 53.3 \% & 60.0 \% & 52.8 \% & 56.7 \% & 57.2 \% & 61.7 \% & 62.8 \% \\ \text { Cosine } & 57.2 \% & 53.9 \% & 53.3 \% & 54.4 \% & 60.0 \% & 52.8 \% & 55.6 \% & 57.8 \% & 61.7 \% & 62.8 \%\end{array}$

Panel B: Return

$\begin{array}{lcccccccccc} & \text { EUR } & \text { JPY } & \text { GBP } & \text { CHF } & \text { SEK } & \text { NOK } & \text { AUD } & \text { CAD } & \text { NZD } & \text { EWP } \\ \text { Gaussian } & 4.20 \% & 0.70 \% & 0.39 \% & 3.16 \% & 4.24 \% & 3.05 \% & 3.70 \% & 4.32 \% & 5.91 \% & 3.30 \% \\ \text { Parabolic } & 5.38 \% & 4.76 \% & 1.61 \% & 4.90 \% & 5.02 \% & 1.49 \% & 6.75 \% & 3.84 \% & 7.86 \% & 4.62 \% \\ \text { Triangular } & 6.55 \% & 4.81 \% & 0.29 \% & 4.44 \% & 6.22 \% & 1.85 \% & 7.26 \% & 3.89 \% & 8.66 \% & 4.89 \% \\ \text { Cosine } & 5.61 \% & 4.76 \% & 1.38 \% & 5.07 \% & 5.36 \% & 1.78 \% & 6.75 \% & 3.78 \% & 8.72 \% & 4.80 \%\end{array}$

\section{Panel C: Sharpe Ratio}

$\begin{array}{lcccccccccc} & \text { EUR } & \text { JPY } & \text { GBP } & \text { CHF } & \text { SEK } & \text { NOK } & \text { AUD } & \text { CAD } & \text { NZD } & \text { EWP } \\ \text { Gaussian } & 0.48 & 0.06 & 0.05 & 0.32 & 0.42 & 0.46 & 0.37 & 0.45 & 0.59 & 0.56 \\ \text { Parabolic } & 0.62 & 0.43 & 0.22 & 0.49 & 0.50 & 0.22 & 0.69 & 0.40 & 0.80 & 0.80 \\ \text { Triangular } & 0.76 & 0.43 & 0.04 & 0.44 & 0.62 & 0.28 & 0.74 & 0.41 & 0.88 & 0.87 \\ \text { Cosine } & 0.64 & 0.43 & 0.19 & 0.51 & 0.54 & 0.27 & 0.69 & 0.40 & 0.89 & 0.83\end{array}$

\section{Panel D: Maximum Drawdown}

$\begin{array}{lcccccccccc} & \text { EUR } & \text { JPY } & \text { GBP } & \text { CHF } & \text { SEK } & \text { NOK } & \text { AUD } & \text { CAD } & \text { NZD } & \text { EWP } \\ \text { Gaussian } & 17.9 \% & 49.9 \% & 26.9 \% & 20.4 \% & 27.6 \% & 12.6 \% & 27.4 \% & 16.5 \% & 26.4 \% & 13.2 \% \\ \text { Parabolic } & 18.6 \% & 28.0 \% & 21.1 \% & 19.7 \% & 22.2 \% & 23.4 \% & 16.9 \% & 29.7 \% & 29.2 \% & 9.8 \% \\ \text { Triangular } & 11.6 \% & 28.0 \% & 32.2 \% & 28.5 \% & 16.8 \% & 20.2 \% & 18.0 \% & 35.1 \% & 24.3 \% & 7.9 \% \\ \text { Cosine } & 18.6 \% & 28.0 \% & 22.3 \% & 19.7 \% & 22.2 \% & 19.1 \% & 16.9 \% & 30.6 \% & 24.3 \% & 9.7 \%\end{array}$

Notes: The table reports the directional accuracy, annualised return, annualised Sharpe ratio and maximum drawdown for the momentum trading strategy based on the Nadaraya-Watson kernel regression using different distributions. The bandwidth parameter is set to one quarter of the inter-quartile range. Results are reported for the G10 currencies and the equally weighted portfolio (EWP). The kernel regression is initially estimated using the sample June 1986 to May 1993. Trading signals are then generated recursively for the period June 1993 to May 2008, by applying an MA(1, 2) trading rule to the estimated non-linear trend. 
Table 5 Trading Strategy Peformance (Moving Average): Sub-Samples

\section{Panel A: Directional Accuracy}

$\begin{array}{lcccccccccc} & \text { EUR } & \text { JPY } & \text { GBP } & \text { CHF } & \text { SEK } & \text { NOK } & \text { AUD } & \text { CAD } & \text { NZD } & \text { EWP } \\ \mathbf{6 / 1 9 9 3 - 5 / 1 9 9 8} & 50.0 \% & 56.7 \% & 45.0 \% & 53.3 \% & 45.0 \% & 51.7 \% & 63.3 \% & 46.7 \% & 55.0 \% & 58.3 \% \\ \mathbf{6 / 1 9 9 8 - 5 / 2 0 0 3} & 66.7 \% & 60.0 \% & 38.3 \% & 56.7 \% & 58.3 \% & 45.0 \% & 48.3 \% & 46.7 \% & 50.0 \% & 53.3 \% \\ \mathbf{6 / 2 0 0 3 - 5 / 2 0 0 8} & 46.7 \% & 53.3 \% & 41.7 \% & 45.0 \% & 48.3 \% & 56.7 \% & 53.3 \% & 46.7 \% & 48.3 \% & 46.7 \%\end{array}$

\section{Panel B: Return}

6/1993-5/1998

6/1998-5/2003

6/2003-5/2008

EUR JPY

GBP

CHF

SEK

NOK

AUD

\section{CAD}

NZD

EWP

$2.44 \% \quad 1.55 \% \quad-2.58 \%$

$2.13 \%$

$5.75 \%$

$0.11 \% \quad 1.58 \%$

$1.73 \%$

$0.60 \%$

$1.48 \%$

$4.62 \% \quad-3.97 \%$

$\begin{array}{ll}6.13 \% & 3.02 \% \\ -3.65 \% & -1.49 \%\end{array}$

$-0.16 \% \quad 5.79 \%$

$2.63 \%$

$7.82 \%$

$4.41 \%$

$2.17 \%$

$-4.14 \%$

Panel C: Sharpe Ratio

$\begin{array}{lcccccccccc} & \text { EUR } & \text { JPY } & \text { GBP } & \text { CHF } & \text { SEK } & \text { NOK } & \text { AUD } & \text { CAD } & \text { NZD } & \text { EWP } \\ \mathbf{6 / 1 9 9 3 - 5 / 1 9 9 8} & 0.29 & 0.13 & -0.37 & 0.19 & 0.72 & 0.02 & 0.16 & 0.19 & 0.09 & 0.41 \\ \mathbf{6 / 1 9 9 8 - 5 / 2 0 0 3} & 1.48 & 0.36 & -0.55 & 0.62 & 0.26 & -0.02 & 0.59 & 0.27 & 0.66 & 0.83 \\ \mathbf{6 / 2 0 0 3 - 5 / 2 0 0 8} & 0.27 & -0.50 & -0.25 & -0.40 & -0.14 & 0.32 & 0.25 & -0.26 & 0.44 & -0.03\end{array}$

Panel D: Maximum Drawdown

$\begin{array}{lcccccccccc} & \text { EUR } & \text { JPY } & \text { GBP } & \text { CHF } & \text { SEK } & \text { NOK } & \text { AUD } & \text { CAD } & \text { NZD } & \text { EWP } \\ \mathbf{6 / 1 9 9 3 - 5 / 1 9 9 8} & 18.1 \% & 29.2 \% & 21.8 \% & 21.7 \% & 9.2 \% & 10.0 \% & 17.3 \% & 22.0 \% & 10.1 \% & 4.3 \% \\ \mathbf{6 / 1 9 9 8 - 5 / 2 0 0 3} & 9.8 \% & 37.8 \% & 41.2 \% & 10.4 \% & 21.9 \% & 20.7 \% & 12.6 \% & 32.5 \% & 11.8 \% & 5.3 \% \\ \mathbf{6 / 2 0 0 3 - 5 / 2 0 0 8} & 10.3 \% & 30.6 \% & 25.1 \% & 21.4 \% & 37.8 \% & 15.1 \% & 12.4 \% & 28.1 \% & 19.4 \% & 9.6 \%\end{array}$

Notes: The table reports the directional accuracy, annualised return, annualised Sharpe ratio and maximum drawdown for the momentum trading strategy based on the MA $(1,2)$ rule over three sub-samples, June 1993 to May 1998, June 1998 to May 2003 and June 2003 to May 2008. Results are reported for the G10 currencies and the equally weighted portfolio (EWP). 
Table 6 Trading Strategy Peformance (Hodrick-Prescott Filter): Sub-Samples

\section{Panel A: Directional Accuracy}

$\begin{array}{lllllllllll} & \text { EUR } & \text { JPY } & \text { GBP } & \text { CHF } & \text { SEK } & \text { NOK } & \text { AUD } & \text { CAD } & \text { NZD } & \text { EWP } \\ \mathbf{6 / 1 9 9 3 - 5 / 1 9 9 8} & 48.3 \% & 61.7 \% & 56.7 \% & 56.7 \% & 61.7 \% & 56.7 \% & 53.3 \% & 50.0 \% & 70.0 \% & 60.0 \% \\ \mathbf{6 / 1 9 9 8 - 5 / 2 0 0 3} & 65.0 \% & 43.3 \% & 51.7 \% & 53.3 \% & 53.3 \% & 41.7 \% & 61.7 \% & 58.3 \% & 56.7 \% & 63.3 \% \\ \mathbf{6 / 2 0 0 3 - 5 / 2 0 0 8} & 55.0 \% & 56.7 \% & 65.0 \% & 43.3 \% & 61.7 \% & 65.0 \% & 50.0 \% & 53.3 \% & 58.3 \% & 58.3 \%\end{array}$

\section{Panel B: Return}

6/1993-5/1998

$6 / 1998-5 / 2003$

6/2003-5/2008

$\begin{array}{ccc}\text { EUR } & \text { JPY } & \text { GBP } \\ 1.60 \% & 10.63 \% & 0.09 \% \\ 8.8 \% & -3.56 \% & 1.87 \% \\ 5.06 \% & 6.04 \% & 5.03 \%\end{array}$

CHF

SEK NOK

AUD

CAD

NZD

EWP

$2.92 \% \quad 3.13 \% \quad 1.75 \%$

$3.16 \%$

$3.44 \%$

$11.74 \%$

$4.27 \%$

$5.97 \% \quad 2.76 \% \quad-1.63 \%$

$10.63 \%$

$7.45 \%$

$8.32 \%$

$4.51 \%$

$0.39 \%$

$8.31 \% \quad 5.02 \%$

$4.81 \%$

$0.03 \%$

Panel C: Sharpe Ratio

6/1993-5/1998

6/1998-5/2003

$6 / 2003-5 / 2008$

$\begin{array}{cc}\text { EUR } & \text { JPY } \\ 0.19 & 0.92 \\ 0.89 & -0.27 \\ 0.65 & 0.74\end{array}$

$\begin{array}{cc}\text { GBP } & \text { CHF } \\ 0.01 & 0.26 \\ 0.26 & 0.60 \\ 0.69 & 0.04\end{array}$

$\begin{array}{cc}\text { SEK } & \text { NOK } \\ 0.39 & 0.41 \\ 0.23 & -0.26 \\ 0.83 & 0.59\end{array}$

AUD
0.32
1.12
0.48

\section{CAD}

0.38

0.79

0.00

NZD

EWP

1.95

0.70

0.89

0.72

Panel D: Maximum Drawdown

$\begin{array}{cccccccccc}\text { EUR } & \text { JPY } & \text { GBP } & \text { CHF } & \text { SEK } & \text { NOK } & \text { AUD } & \text { CAD } & \text { NZD } & \text { EWP } \\ 16.5 \% & 16.7 \% & 12.1 \% & 22.0 \% & 10.9 \% & 7.4 \% & 15.5 \% & 14.7 \% & 3.2 \% & 4.1 \% \\ 10.5 \% & 32.5 \% & 17.9 \% & 18.7 \% & 31.6 \% & 26.8 \% & 8.8 \% & 11.2 \% & 24.3 \% & 7.1 \% \\ 11.4 \% & 7.3 \% & 6.0 \% & 23.7 \% & 11.2 \% & 8.5 \% & 11.8 \% & 32.3 \% & 15.9 \% & 7.7 \%\end{array}$

Notes: The table reports the directional accuracy, annualised return, annualised Sharpe ratio and maximum drawdown for the momentum trading strategy based on the Hodrick-Prescott filter over three sub-samples, June 1993 to May 1998, June 1998 to May 2003 and June 2003 to May 2008. Results are reported for the G10 currencies and the equally weighted portfolio (EWP). 
Table 7 Trading Strategy Peformance (Nadaraya-Watson Kernel Regression): SubSamples

\begin{tabular}{|c|c|c|c|c|c|c|c|c|c|c|}
\hline \multicolumn{11}{|c|}{ Panel A: Directional Accuracy } \\
\hline & EUR & JPY & GBP & CHF & SEK & NOK & AUD & CAD & NZD & EWP \\
\hline 6/1993-5/1998 & $55.0 \%$ & $60.0 \%$ & $46.7 \%$ & $63.3 \%$ & $61.7 \%$ & $50.0 \%$ & $56.7 \%$ & $58.3 \%$ & $68.3 \%$ & $66.7 \%$ \\
\hline 6/1998-5/2003 & $60.0 \%$ & $45.0 \%$ & $51.7 \%$ & $50.0 \%$ & $55.0 \%$ & $43.3 \%$ & $60.0 \%$ & $60.0 \%$ & $50.0 \%$ & $61.7 \%$ \\
\hline 6/2003-5/2008 & $55.0 \%$ & $56.7 \%$ & $63.3 \%$ & $48.3 \%$ & $61.7 \%$ & $63.3 \%$ & $50.0 \%$ & $56.7 \%$ & $61.7 \%$ & $60.0 \%$ \\
\hline \multicolumn{11}{|c|}{ Panel B: Return } \\
\hline & EUR & JPY & GBP & CHF & SEK & NOK & AUD & CAD & NZD & EWP \\
\hline 6/1993-5/1998 & $4.04 \%$ & $9.50 \%$ & $-0.66 \%$ & $7.69 \%$ & $2.59 \%$ & $0.59 \%$ & $6.75 \%$ & $5.02 \%$ & $11.29 \%$ & $5.20 \%$ \\
\hline $6 / 1998-5 / 2003$ & $7.0 \%$ & $-1.27 \%$ & $1.47 \%$ & $4.50 \%$ & $4.65 \%$ & $-0.28 \%$ & $8.69 \%$ & $7.98 \%$ & $3.12 \%$ & $3.99 \%$ \\
\hline 6/2003-5/2008 & $5.06 \%$ & $6.04 \%$ & $4.02 \%$ & $2.51 \%$ & $7.81 \%$ & $4.14 \%$ & $4.81 \%$ & $-1.49 \%$ & $9.18 \%$ & $4.68 \%$ \\
\hline
\end{tabular}

$6 / 1993-5 / 1998$
$6 / 298-5 / 2003$
$6 / 2003-5 / 2008$

$\begin{array}{cc}\text { EUR } & \text { JPY } \\ 0.48 & 0.82 \\ 0.71 & -0.10 \\ 0.65 & 0.74\end{array}$

Panel C: Sharpe Ratio

$\begin{array}{cccccccc}\text { GBP } & \text { CHF } & \text { SEK } & \text { NOK } & \text { AUD } & \text { CAD } & \text { NZD } & \text { EWP } \\ -0.09 & 0.71 & 0.32 & 0.14 & 0.70 & 0.56 & 1.85 & 1.09 \\ 0.20 & 0.45 & 0.40 & -0.04 & 0.90 & 0.85 & 0.26 & 0.64 \\ 0.55 & 0.28 & 0.78 & 0.48 & 0.48 & -0.15 & 0.88 & 0.74\end{array}$

Panel D: Maximum Drawdown

$\begin{array}{ccccccccccc} & \text { EUR } & \text { JPY } & \text { GBP } & \text { CHF } & \text { SEK } & \text { NOK } & \text { AUD } & \text { CAD } & \text { NZD } & \text { EWP } \\ \mathbf{6 / 1 9 9 3 - 5 / 1 9 9 8} & 11.2 \% & 19.5 \% & 12.9 \% & 16.7 \% & 11.0 \% & 14.4 \% & 13.9 \% & 9.2 \% & 3.4 \% & 4.2 \% \\ \mathbf{6 / 1 9 9 8 - 5 / 2 0 0 3} & 18.6 \% & 28.0 \% & 21.1 \% & 19.7 \% & 22.2 \% & 23.4 \% & 16.9 \% & 11.2 \% & 29.2 \% & 9.8 \% \\ \mathbf{6 / 2 0 0 3 - 5 / 2 0 0 8} & 11.4 \% & 7.3 \% & 9.7 \% & 13.6 \% & 13.7 \% & 10.9 \% & 11.8 \% & 27.0 \% & 12.9 \% & 6.8 \%\end{array}$

Notes: The table reports the directional accuracy, annualised return, annualised Sharpe ratio and maximum drawdown for the momentum trading strategy based on the Nadaraya-Watson kernel regression over three sub-samples, June 1993 to May 1998, June 1998 to May 2003 and June 2003 to May 2008. Results are reported for the G10 currencies and the equally weighted portfolio (EWP). 